\title{
中國动物生态学家的当前任务
}

\author{
林昌㦈㳵汝稘
}

（北京大学生物系）

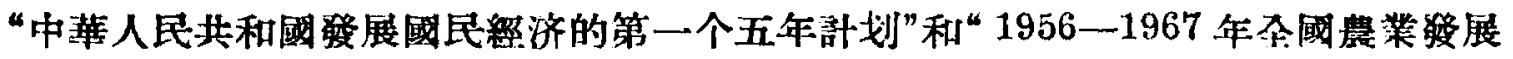

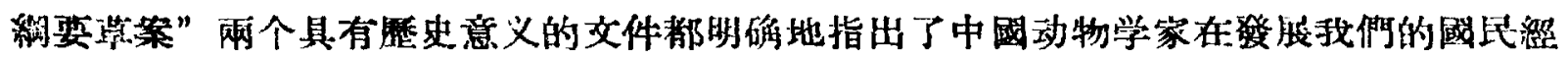
济方面所应担当的光荣而艰巨的任务。

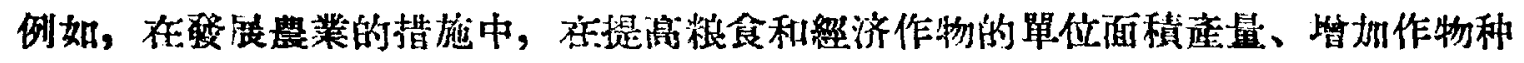

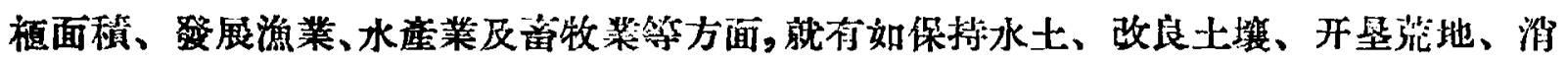
減病害虫害、㘿加度最、提高質量等問題。这些問題無一不与生物学和动物学的研究有 关。为了更好地解决上面所提出的一系列的問还, 动物学工作者必須淮行研究一种比較 年䡛的动物科学, 即动物生态学。

按其定义、基本內容以及其所研究的范图而言, 动物生态学是在辩許唯物主义理論的 基碟上桃研究动物有机体与决定其生活方式的环境二者之間相互关系的科学。在动物科 学的喔域中，形态学研究有秃体的結棈,生理学研究有机体的各个器官和其整体的机能, 而生态学所研究的是它的生活方式与形态、机能以及其外界罘境的相互关系。动物存机

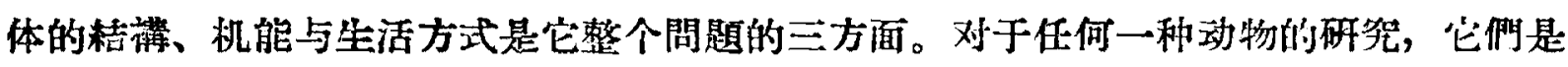
三位一体，缺一而不可的。动物学工作者在國民經济建設中所起的作用是保护和繁殖对

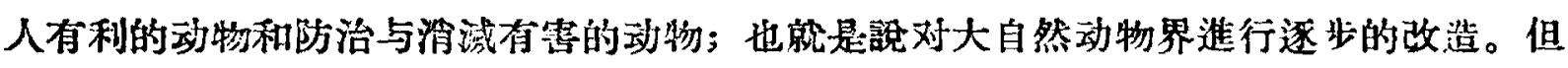

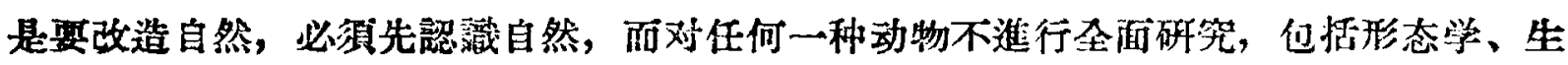
理学与生态学的研究，全面的認亚是不仃能的。

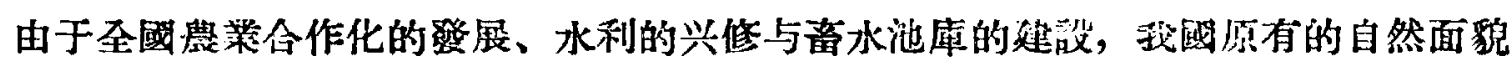

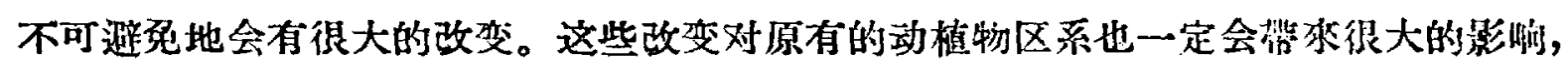
促成它們在生活方式上的根本改变和利群成你和数聂的巨大变迁。同时这就白拉國动物 生态学方面琵出新的問面，而这些問題也必須从新的研究中独解决。在这些問題得到解

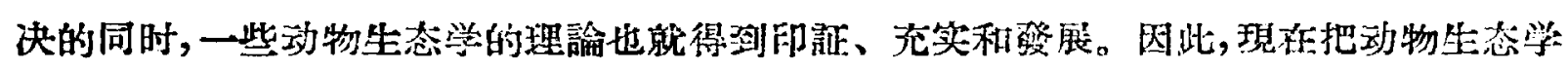

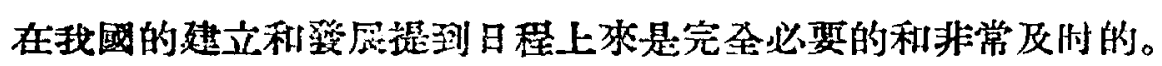

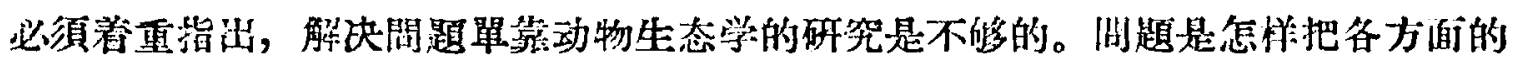

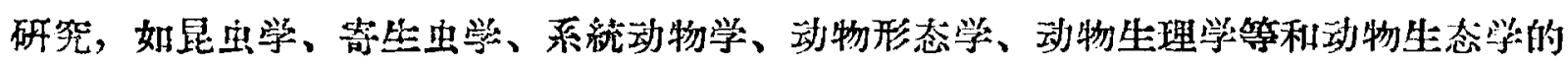
研究配合起来。而且更重要的是如何便以上所列举的科学家們对生恣学方面的工作給以

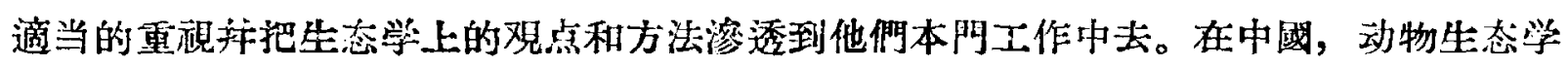
不僅僅是一阴年輕的科学, 而且几乎是一个空白点。为了加强和加速这一阿科学的弡展,

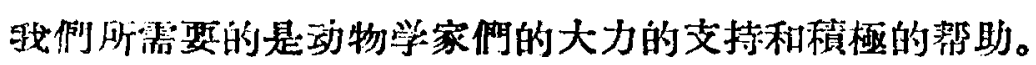




\section{一 目前國际动物生态学的筑况}

在西欧动物生态学成为一門独立的科学可以虽是从十九鉦紀六十到七十年代开始。 德國的赫克尔在 1869 年头一头使用 Oekologie（德交的生态学）这个名詞科給了它一个 定义，大体上規定生态学应研究的范圍。但是应該說在此以前西欧的动物学家已經淮 行了很多有关生态学的研究。这些工作都包括在其他科学范囯之內, 其中比悛重要的是 动物生理学, 特別是“动物發生生理学”与“动物反应生理学”。研究的目的是把动物或动 物的肧胎放在不同环境之下（如温度、湿度、光綫等非生物环境）爽淮行覌察环境的改 变对动物的肧胎發有或成体活动所發生的影响。此外，在动物学的一般記傤上酒，自希 䱋的亞里斯多德起就已注意到动物与其生活环境关系的問題。后來自然歷史学家在欧洲 的十七和十八世紀与分类学家在一起地筸大力搜集了有关这方面的資料。有些自然歷史 学家如英國的达尔交与華雷斯, 根据他們个人的覌察和总結前人的經驗曾建立了动物進 化的理諭。在这里他們运用了很多有关动物生态学的資料。

正是因为这样的原因，有些动物学家認为生态学的前身是动物的自然歷史。进至有

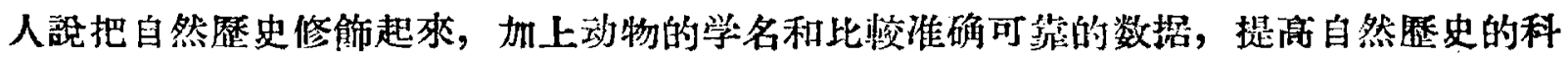
学性, 就能把它变成动物生态学。我們認为这利看法是不佮当的, 因为它忽略了动物生 态学里的生理部分以及在实驗室內所獲得的資料。另外，必須指出，就是在資本主义的 國家内, 这叫科学出具有应用方面的意义, 与水生生物学、海洋学、湖沼学以及动物地 理分们学等保持者密切的联系。

椡了本世紀, 动物生态学在西欧已成辰为一个独立的科学, 具有自己的研究范園和 基本內愘。但是在二十年代之前，所有的研究仍是沿着十九圤紀末已經开始的路馢進行 的。自二十年代起，以厄尔頓 (Elton)为首的英國学派开始進行了一些綜合性的研究，从 而得出一些有关动物生态学本身的理論, 主要地涉及到生物群落与动物种群中的閣題, 如 “小生境” (Niche)、“食物鋉”等。在英國原有“生态学雜志”, 而在 1932 即由这个雜志分出 动物生态学自己的刊物, 即“动物生态学雜志”。这也證明它的發展已到了一个新的階段。

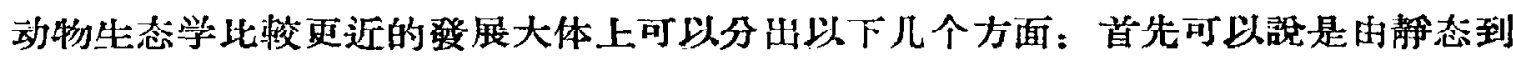
动态, 的現像的描述到对它的分析。就以种群的閣題为例, 以往的研究是着重在类群实 际数目的調查，現在已䡜向数量的增减和种群消長的分析。这就不可避免地要看一看环 境对种群的影响以及物种数量的加塯与动物分布的关添等。其次，们以䚺是们以徍把影 响因素孤立起來到把个別因子綜合一起來看問題。例如閆名的动物生态学家博登亥莫尔 (Eodenheimer) 在他最近出版的“动物生态学簡編” (“Drecis D'Ecologie Animole”1955)

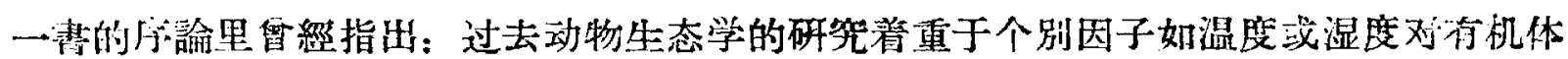
的影响，而目前却更多地考虑到整个环境因素对有机体綜合的影响。这可以說是代表着 紹大多数西欧动物生态学家的看法。

再其次，我們看到动物生态学的研究的范園一方面与动物生理学，特別是比校动物 生理学更形接近，另一方面又与形式遭傳学携起手承。这样，这二門科学的界限就有些 不大容䀛区分。但是它們仍然不失为独立的科学部門，因为就以生态与生理学而論，前 者研究对像的最大單位不超过动物个体。生态学研焭的主要对象則是种群或群落, 它虽 
然也沙及机能与活动等問題, 但对它們的看法只是作为动物生活方式与环境关系的一种 表現。生态学研究的范蒚既然比生理学更为展閣一些, 所以也就不一定能深入到个体活 功的机制閭題。

动物生态学家与遗傳学家都对动物演化的問題隻行了研究, 因而在这样一个范阅內,

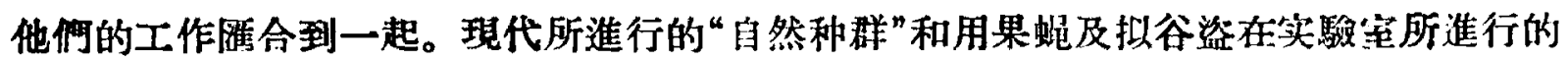

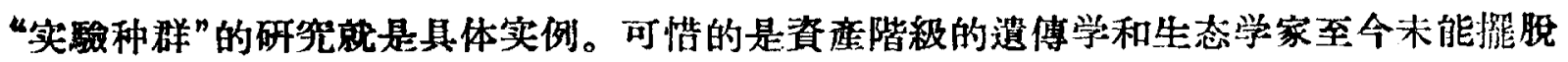

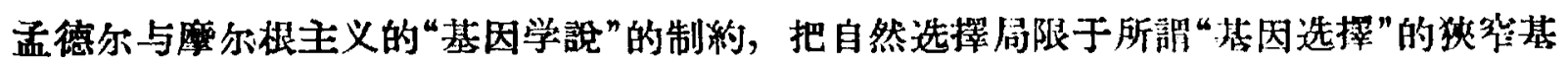
礎上。同时从这样一个覌点出發來裙找出路, 許多学派嫁陷入于强調数学公式与生物統 部方法在生态学上所起的作用, 把整个生态学的研究变成数学的附屬物。

但是不可否認在研焭的技術和方法上面, 資本主义國家的生态学家和其他生物科学 家一样充分利用了現代物理学、地質学、“侯学、气象学、海洋学、动植物地理学等最 新的成就。这就很自然地望皘了大量很精細和富有內容的資料。另外，在所偝“古生态 学”方面，他們也淮行了一些工作，米具有很大的發展前途。

在十九世紀的俄國和后爽的苏联, 动物生态学的發展一开始就循着另一条路绕進行 的, 即以有机体与环境的統一为其理論基礁。早在 1854 年, 莫斯科大学动物学教授K.Ф.

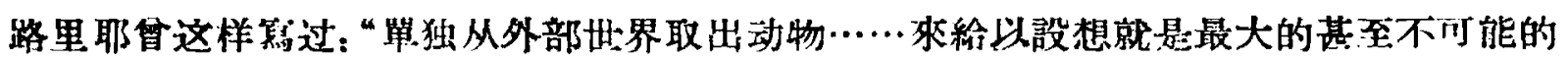
奇觔。这就是我們何以把动物和外部世界的艾徒作为区分其器苢和机械的基整……; 根 据同样的原因, 可以把同一思想作为覌察完整动物的一切現像、它的生活方式和㥜性的

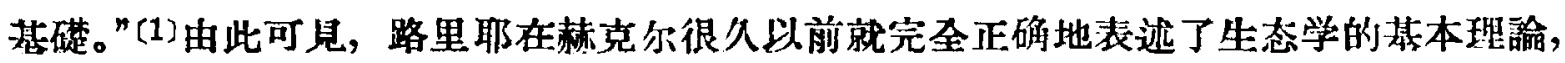
趴关于有机体与环境的統一和有机体本身的䊅構与机能在適应上的統一。茄联現代动物

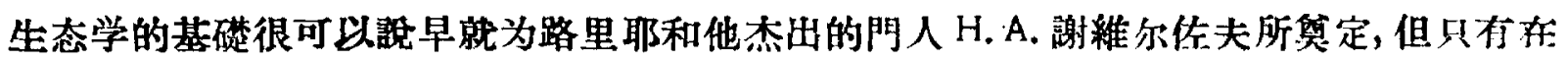
苏联社会主义的制度下，这門科学才得到很大的發展。

1954 年 12 月在基輔石开的 全苏第三届动物生态学会議和在会上所作出的决議代社 着动物生态学在社会主义國家發展道路上的最重要的里程碑。在这个碑上到滿了过去的 偉大成就，同时也規划出來将來的涭展。因此，这个会議的整个內容是值得我們学㹦的。(2)

从这个会議的总結报告，首先我們可以看出湙联的动物生态学家以㣖和現在总是沿 着傳統的唯物主义的道路向前迈進。他們的研究是和苏联國民維济建設保持着密切联系 的。他們已程解决的和將要解决的問題多是苏联共座党和政府提到日程上爽的間題。在

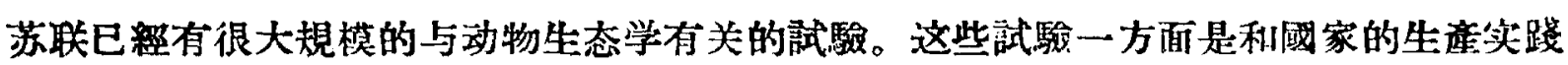
相联系着，另一方面有很多不同部門的專家集体地参加了工作。这些試验涉及到農業、林 業、畜牧業、皮毛鄂飼养業、漁業以及医薬衛生等方面的問題。在这些方面，苏联似动 物生态学家都取得一定的成就。

其次，我們也可以看出，苏联生态学家特別重視理諭的研究工作。有碎多在全体大 会上宜謮的論交都涉及到最先進的生态学理論原則。不僅如此，大会的决議还指出：为 了淮一步更有效的解决國民緅济上所提出的实际問題，心須㨜大具有重要方法論意义的 理論性的研究。在这議策里挂提出以下儿項作为首要的問題本研究：

(1) J. B. 尼科里斯基: “动物生态学的內容、理諭基礎和基本任务”，科学出版社，1955 年 11 月。

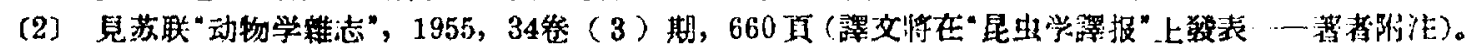


“1. 动物的种內与种間关系, 依生态条件为轉移的动物生理学和形态学的特征及其 变动。

2. 种群及在种內的其他类群对不断改变着的外界环境条件的適应姓的發展途徑及規 律。

3. 有机体数量改变的規律以及种群在其發展条件的影响下，形态生理特征形成的規 律。

4. 与生存条件相联系的种內变异性的意义。

5. 生物群落的展与形成的規律（为了拟訂有关减少有害物种数量与增加有篮物种 数量的具体指施)"

此外, 大会决議还指出: 从生态学研究已有的試驗出發, 現代生态学的基本內容有 以下三个主要方面:

“1. 研究有机体的种的蔐应性及其歷史工上的制約性，作为了解有机体与环境的多式多 样相互关系的基礎。

2. 研究种群形成及其發展規律, 将种群作为种的一种生存形式, 研究利群分化及其 数量的变动。

3. 研究生物群洛的形成及其發展規律, 將生物群落作为各种有机体在具体生活环冼 条件下的相互关系的表現。”

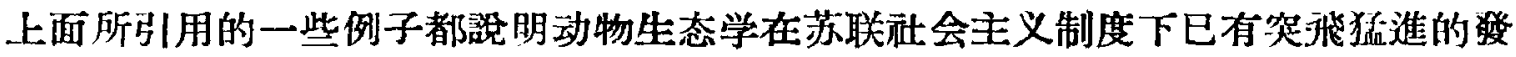
展，来正在大踏步地向前迈進。同时，应該肯定，这次会議所指示的方向也就是我們在中國 应硋走的方向。

\section{二 擺往中國动物生态学家面前的任务和一些具体的問題}

旧中國的动物学家都兽跟在资本主义國家学者的后面多少走了一段弯路，因此像动 物生态学这阿科学晌未獾得应有的重視。解放后, 在党和毛主席的号召下，我們开始学 㥜苏联，从而在科学研究方面开辟了一些新的方向。动物生态学的研究在昆虫、海洋生 物与水生生物方面結合生座的需要都進行了一些研究; 但是对整个动物界桃說做的还是 非常不所，就是已做的也不过是一个开始。因此, 正如我們在前面所說的, 动物生态学的 研究在中國还几乎是一个空白点。缺乏动物生态学的研究不等于說在中國沒有生态学的 問題。攏在中國动物生态学洎前的任务还是非常明确的，那就是繼續不断地提高我們的 生站, 从而为建設社会主义塥会而服务。

要勝利完成这項任务，我們必須沿着以下雨个途徑進行工作: (一)研究如何使 我們 原有的动植物群落不断地增產; (二) 發現新的或利用不足的动植物群落使其不断的得到 开拓。动物生态学的任务, 一方面是揭發和闈明原有生物群落的結橴、形成的过程、数量 的变动及其他發展規律。根据这样的規律损出合理使用和加强保护有經济价值的生物的

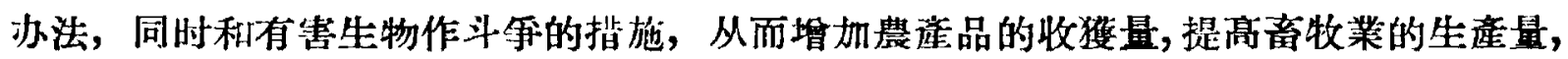

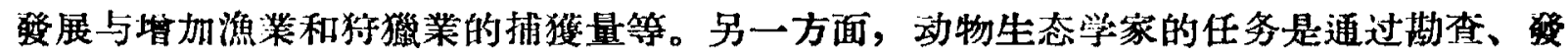

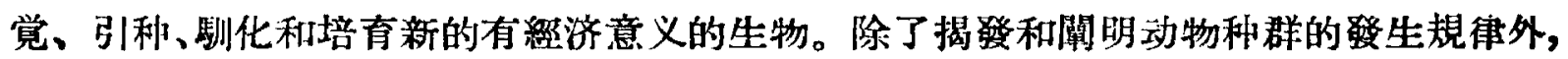
还要拟出对这些新的有經济价值的动物的数量变动合理的控制。 
所有这些虽詋是生迹实践的問題但必須从理論的研究入手。最近周总理在关于知满 分子問題的报告中每指示: “……到了現在, 如果我們还不及时地加强对于長远需要和理

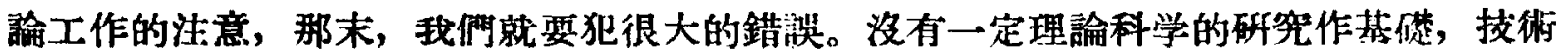

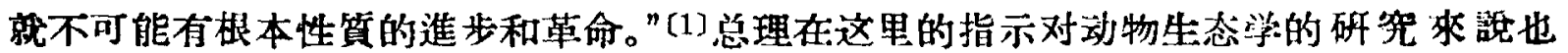
是证确的和及时的。

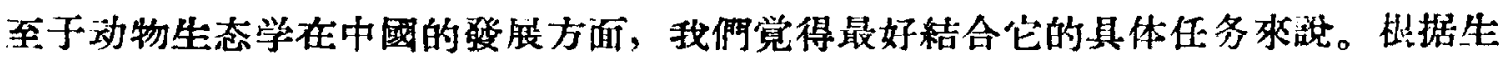

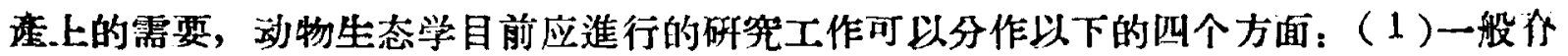
椎动物；（2）水生生物（包括㷛类）；（3）昆虫；（4）窨生动物。

\section{（1）一般脊椎动物的生态学}

有关理論方面的問題，例如:

1. 生态区系的划分：必須進行全國各地动物种类，特别是具有經济价值的科类的晋 查工作，然后按其生态条件划分区系。这可以作为动物資源調查、分类以及生态等碑究 的基礎，因而也就是基本工作。我們建䉝，这項工作应該由科学院及有关部門組織全國 力量, 分区調查, 限期完成。

2. 生活型的分类：这是生态学及动物地理上重要問題之一，扭对于了解物种適应具 有重大意义。

3. 种間与和內关系：这是当前生物界孚辯最激烈的問題; 生态学的研究将会对这方 面提供肎貴䝿料。

4. 人类活动对生物群落的影响：在租國大規模的䅘济建設和自然改造中，生物群落 的变动是可以想像的。如果能够有意識進行这方面的研究, 会对生物群落的㜊展規律有 所揭露。

有关生应实踐的問題:

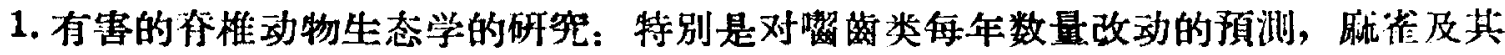
他危害農業、林業等的动物的行为及数量的变化, 特別洼意磨烄在大力捕捉后数最的变 迁和恢复。

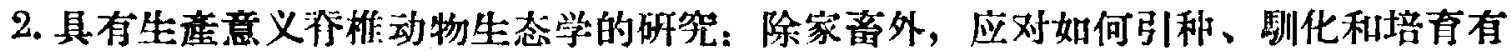

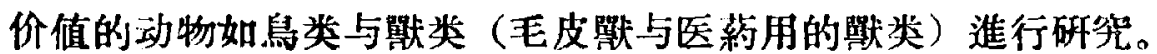

3. 禁獵区与生态覌察站: 就我們所知, 我們还没有一定的禁獵区和猕猴法; 它們的 設立和制定，从生态学的覌点来看是刻不容楥的。生态覌察站既可以設在禁猴区內，也可 以在全國的不同生态的地区。在禁垤区内应特別注意动物数量的变更和進行調尘数量方 法的研究。必須把迁移烏的管理和覌祭包括在內。对于世界希少珍奇的动物如猫熊等应 淮行大力保护汼做一些生态学的研究。

\section{（2）水生生物生态学}

关于理論方面的研究:

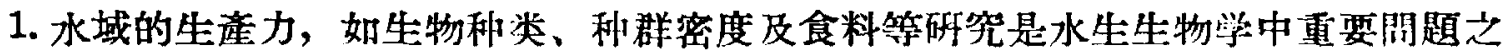
一。这些研究对于我國漁業有很大意义。这里应包括增殖、漁㬳、産力测定与計划生商 等問題的具体研究。

(1)“关于知識分于閭題报告”，人民日报，1956 年 1 月 30 日。 
2. 魚类及無悀椎动物水産区系及其生态地理分布規律的研垫。

3. 水生动物数量变动的規律包括魚类能料基物数量变动的規律及其影响因素，作为 預測魚群、凅訊数量的基礎。

4. 水城的理化、水交及生物等特征与水生动物的营养、繁列、生長發有以及形态生 理的適应問題的研究。

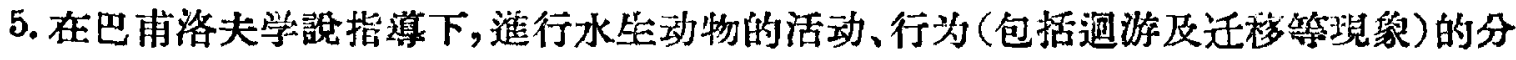

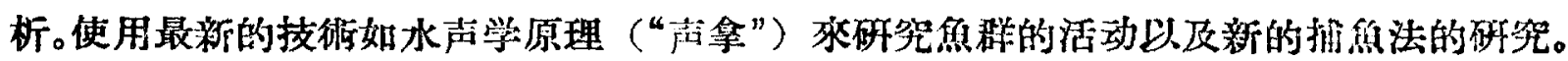

6. 人类活动影响下所産生的水生生物生态学問題的研究，例如水利、灌餀、污化、水 庫等非生物（气候、水交、化学变迁等）与生物体系形成啲猊律。

有关生噇实踐的問题:

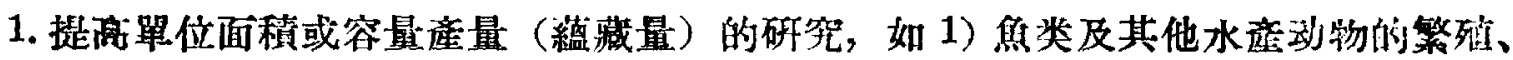

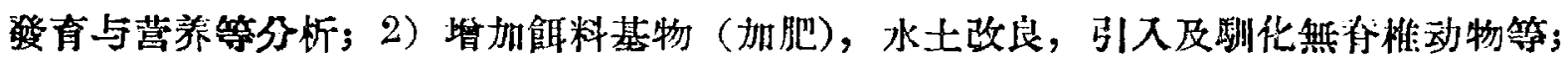

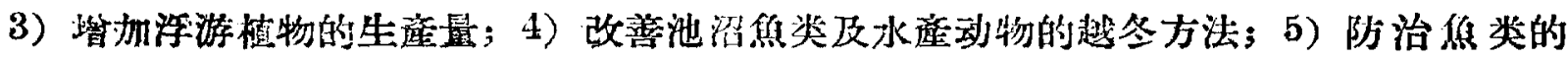

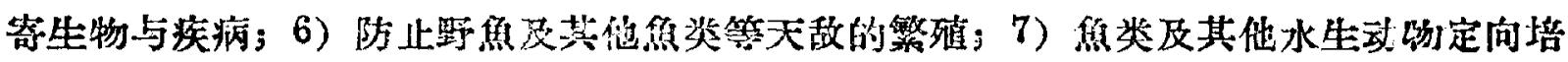
有的研筦等。

2. 第苗与魚种的生物生态学的研究，如 1) 它們的生活、發有及繁殖的生态学; 2)

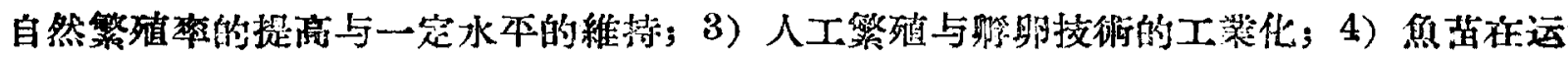

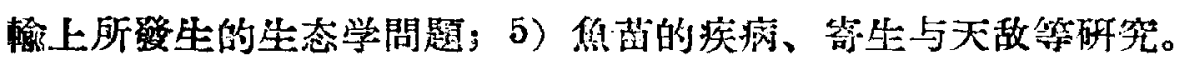

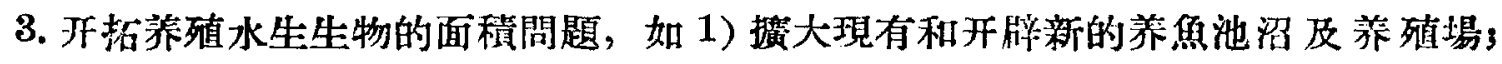

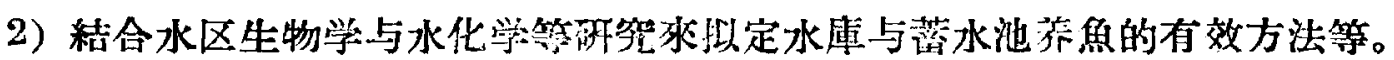

（3）昆虫生态学: 在理馀方面, 我們認为目前昆虫生态学有以下三个中心問題:

1. 昆虫种的適应与進化，包括以下的研究：1）非生物条件对昆虫有机体的發育、生 長与繁殖的影响；2）种在生理、形态、肧胎發笲和生态上的適应性；3) 种內与种間关 系；4）种的形成过程及其理論。

2. 昆虫（他括缊虫与害虫）的發生規律有以下的研究：1）种群数量变动的原因及其 貌律；2）害虫發生基地（策源地）的形成及其变迁的規律；3）害虫發生的預湘預报的 生物学和生态学的基礎。

3. 昆虫分布的規律，们括以下的研究：1）生态区系的划分及其原則；2）昆虫份布 的歷史，自然和人为的因素；3）有关昆虫生物群落的組成及其变迁。

下面我們也略举一些具有实踐意义的問題:

1. 七大害虫及其他重要地方性的害虫应着手淮行其發生規律的研究，作为預測頂报 及防治措施的根据。設立昆虫生态覌察站是必要的。为了做好預测預报工作，昆虫生态 学家应与植物学部阴配合起隶, 淮行昆虫的物候学的研究 (例如蚊虫的物候学等)。

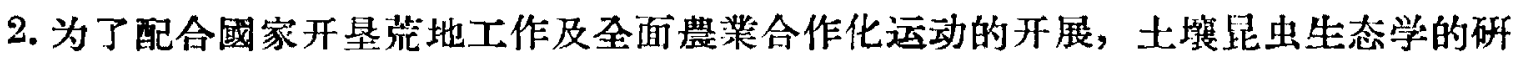
究是極有意义的，如土壤昆虫区系的划分，在荒地及新开量地上的有害昆虫的形成及其 形成的規律，在新灌溉地与不同耕作制度下土壤昆虫区系的形成及其数量变动的規律。

3. 在扑隇害虫方面的生物防治, 如对于害虫天敌的保护、利用、养殖、馿化、引入，特别 是化学防治与生物防治的配合等都应該予以重視和研究。䇬食性昆虫的行为(如集群越冬

7 月号

科学通报

- 47 . 


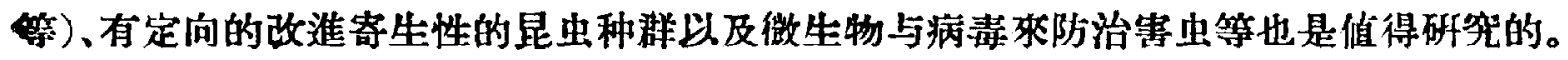

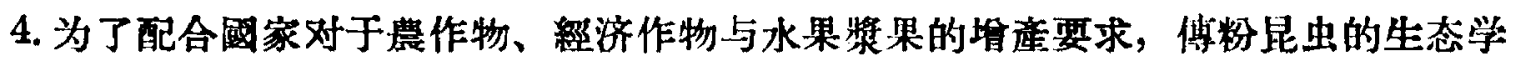
与其保护是重要的，特別是要洗意䖝蜂等益虫对㘿加座量的关系。

5. 由于國家僻备粮食的增加，在粮食保管中，倉庫害虫的問題顯得突出，从而倉庫 害虫的张条件与其规律的研究是这方面的中心問題。

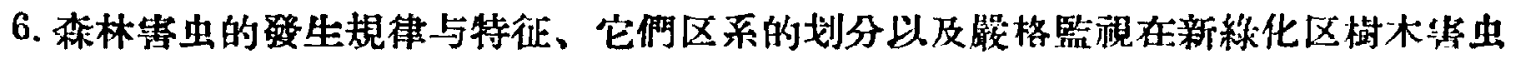
的然。

7. 在医䒚昆虫生态学上应該注意蚊䗷的行为、越冬、溪生地的分布、环境条件以及数 量的李節性变化等 (参考以下奇生物部分)。

8. 昆虫生态学家应对國队或國际間的松投措施提供以生态学为基礎的科学資料。

（4）寄生动物的生态学: 在寄生动物学的領城中，甜們認为同样地地应該重視理 諭的研究，例如:

1. 奇生动物与宿主的关系：如 1) 奇生动物在形态与机能上的適应性（异样性 或分 化)；2）缩主的抗病性与免投性的等物学与生态学的基整；3）奇生动物侵繁宿主的非 生物与生物（如缩主的生理狀况等）条件的生态学研究等。

2. 奇生动物的种群与群落，包括：1）奇生动物种群数量变动的忋律；2）奇生动物 的种队与种間关系，3）寄生群落形成原因 (發生学) 与变迁 (动力学) 等。

3. 奇生动物的起源与分质：如1)奇生动物的起源与其生态学上的关系；2)奇生动物 的分布规律及其原因；3）缩主轉換与新种形成的問題等。

与实踐有关的奇生动物生态学的問題:

1. 人类与家青奇生流行病發生規律的研究。

2. 魚类及其他有經济价值动物寄生疾病的病原虫的生态学問題。

3. 在巴甫洛夫斯基自然疫源学䛸指導下，進行芫地及新开量地野生动物及其吸血的 体外奇生物群落的研究。

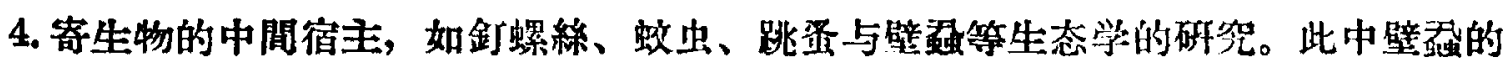
分类与生态学的研究尤应加强; 正如 1954 年所不开的全苏生态学会議仅问年分开的全

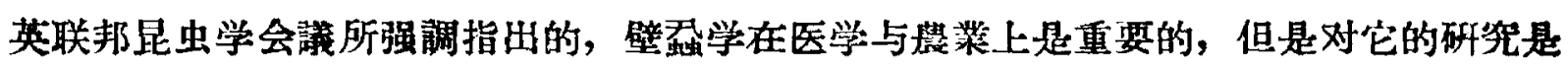
非常不够的。

5. 城郷人者落便处理与肥料問題的研究等。

对于上面所提出的問題, 不言而猗, 都应罙用最新的和最有效的方法來淮行研究。 在尽可能的条件下尤应大量使用生物物理学的方法、同位素与示踪原子等。

党和政府正在領導規划怎样使我國主要的科学部阴在十二年內接近國际先進水平。 执肶覚得首先应該肯定动物生态学在动物学中是主要研究方向之一，从而应該給以足的 的重視。其次，領導方面世应該給了这个几乎等于一个空白点的科学部門以人力和物質 的大力支持。再其次, 在規划这門科学發展前途时更应該无分佔計其有利条件（如我們有

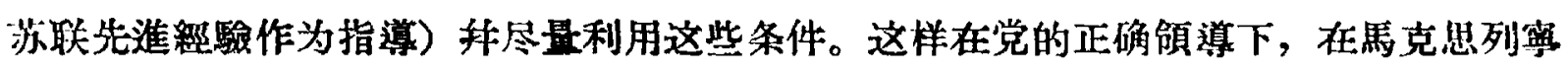
主义理諭的照耀下，在苏联科学家兄弟般的帮助下，加上我的最大努力，那就完金有可 记，在指定的时期內完成我僻党和人民給我們的光荣而偉大的任务。 